Bond University

Research Repository

Fused Twins: A Cognitive Approach to Augmented Reality Media Architecture

Grübel, Jascha; Gath-Morad, Michal; Aguilar, Leonel; Thrash, Tyler; Sumner, Robert W.; Hölscher, Christoph; Schinazi, Victor

Published in:

Proceedings of the 5th Media Architecture Biennale Conference, MAB 2020

DOI:

$10.1145 / 3469410.3469435$

Licence:

Other

Link to output in Bond University research repository.

Recommended citation(APA):

Grübel, J., Gath-Morad, M., Aguilar, L., Thrash, T., Sumner, R. W., Hölscher, C., \& Schinazi, V. (2021). Fused Twins: A Cognitive Approach to Augmented Reality Media Architecture. In Proceedings of the 5th Media Architecture Biennale Conference, MAB 2020 (pp. 215-220). (ACM International Conference Proceeding Series). Association for Computing Machinery (ACM). https://doi.org/10.1145/3469410.3469435

\footnotetext{
General rights

Copyright and moral rights for the publications made accessible in the public portal are retained by the authors and/or other copyright owners and it is a condition of accessing publications that users recognise and abide by the legal requirements associated with these rights.

For more information, or if you believe that this document breaches copyright, please contact the Bond University research repository coordinator.
} 
Bond University

Research Repository

\section{Fused Twins: A Cognitive Approach to Augmented Reality Media Architecture}

Grübel, Jascha; Gath-Morad, Michal; Aguilar, Leonel; Thrash, Tyler; Sumner, Robert W.; Hölscher, Christoph; Schinazi, Victor

Published in:

Proceedings of the 5th Media Architecture Biennale Conference, MAB 2020

DOI:

$10.1145 / 3469410.3469435$

Link to output in Bond University research repository.

Recommended citation(APA):

Grübel, J., Gath-Morad, M., Aguilar, L., Thrash, T., Sumner, R. W., Hölscher, C., \& Schinazi, V. (2021). Fused Twins: A Cognitive Approach to Augmented Reality Media Architecture. In Proceedings of the 5th Media Architecture Biennale Conference, MAB 2020 (pp. 215-220). (ACM International Conference Proceeding Series). Association for Computing Machinery (ACM). https://doi.org/10.1145/3469410.3469435

\footnotetext{
General rights

Copyright and moral rights for the publications made accessible in the public portal are retained by the authors and/or other copyright owners and it is a condition of accessing publications that users recognise and abide by the legal requirements associated with these rights.

For more information, or if you believe that this document breaches copyright, please contact the Bond University research repository coordinator.
} 


\section{Fused Twins: A Cognitive Approach to Augmented Reality Media Architecture}

JASCHA GRÜBEL*, MICHAL GATH-MORAD*, and LEONEL AGUILAR*, ETH Zürich, Switzerland TYLER THRASH, Miami University, United States of America

ROBERT W. SUMNER, ETH Zürich, Switzerland

CHRISTOPH HÖLSCHER, ETH Zürich, Switzerland

VICTOR R. SCHINAZI, Bond University, Australia

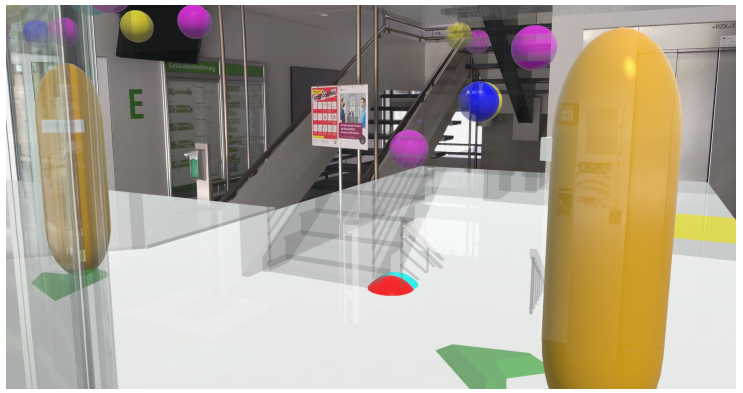

(a) Entering the augmented lobby in the Fused Twins.

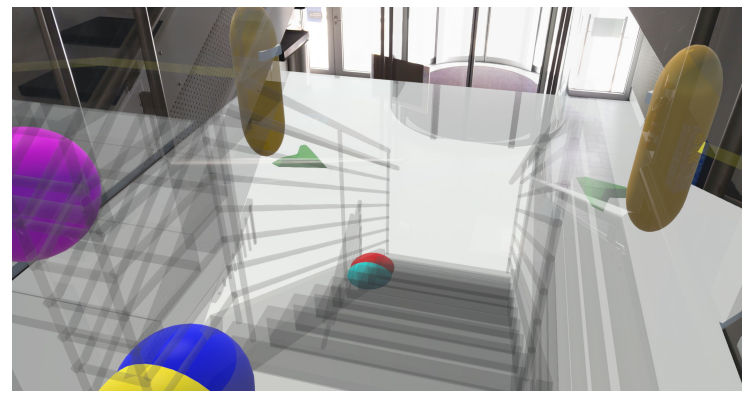

(b) Coming down the stairs into the augmented lobby.

Fig. 1. The Fused Twins are used to augment the building's lobby with visualizations of sensors and agents through a HoloLens 2.

Recent advances in Augmented Reality (AR), the Internet of Things (IoT), cloud computing, and Digital Twins transform the types, rates, and volume of information generated in buildings as well as the mediums through which they can be perceived by users. These advances push the standard approach of media architecture to embed screens in the built environment to its limits because screens lack the immersive capacity that newer media afford. To bridge this gap, we propose a novel AR approach to media architecture that uses a Digital Twin as a platform for structuring and accessing data from various sources, including IoT and simulations. Our technical contribution to media architecture is threefold. First, we extend the possibilities of media architecture beyond embedded screens to three dimensions by presenting a Digital Twin using AR with a head-mounted display. This approach results in a shared and consistent augmented experience across large architectural spaces. Second, we use the Digital Twin to integrate and visualize real physical sensor information. Third, we make artificial occupancy simulations accessible to everyday users by presenting them within their natural context in the Digital Twin. Observing the Digital Twin in situ of the Physical Twin also has applications beyond media architecture. Fusing the two twins using AR can reduce the cognitive load of users from consuming big and complex information sources and enhance their experience. We present two use cases of the proposed Fused Twins in a university building at ETH Zürich. In the first use case, we visualize a dense indoor sensor network (DISN) with 390 IoT sensors that collected data from March 2020 to May 2021. In the second use case, we immerse visitors in agent-based simulations to enable insights into the real and projected uses of space. This

*All three authors contributed equally to this research.

Permission to make digital or hard copies of part or all of this work for personal or classroom use is granted without fee provided that copies are not made or distributed for profit or commercial advantage and that copies bear this notice and the full citation on the first page. Copyrights for third-party components of this work must be honored. For all other uses, contact the owner/author(s).

(c) 2021 Copyright held by the owner/author(s).

Manuscript submitted to ACM 
work brings forward an ambitious vision for media architecture beyond traditional flat screens, and showcases its potential through fusing state of the art simulations, sensor data integration and augmented reality, finally making the jump from fiction to reality.

CCS Concepts: • Human-centered computing $\rightarrow$ Visualization systems and tools; Mixed / augmented reality; Ubiquitous and mobile computing systems and tools; $\bullet$ Applied computing $\rightarrow$ Computer-aided design; $\bullet$ Computing methodologies $\rightarrow$ Mixed / augmented reality.

Additional Key Words and Phrases: Fused Twins, Augmented Reality, Digital Twin, Physical Twin, Agent-Based Modeling, Dense Indoor Sensor Networks, Data-Driven Design

\section{ACM Reference Format:}

Jascha Grübel, Michal Gath-Morad, Leonel Aguilar, Tyler Thrash, Robert W. Sumner, Christoph Hölscher, and Victor R. Schinazi. 2021. Fused Twins: A Cognitive Approach to Augmented Reality Media Architecture. In Media Architecture Biennale 20 (MAB20), June 28-fuly 2, 2021, Amsterdam and Utrecht, Netherlands. ACM, New York, NY, USA, 8 pages. https://doi.org/10.1145/3469410.3469435

\section{INTRODUCTION}

In the era of big data, media architecture is limited by its focus on the medium of 2D screens and 2D projections. Whereas media architecture has extended beyond aesthetically pleasing art installations to interactive façade mapping [13], place-making and participation [8, 16, 18, 23], health [41], and design [42], it remains unprepared to address the underlying abundance of raw spatio-temporal data. In contrast, Augmented Reality (AR) technologies enable the consumption of big data in its spatio-temporal context, allowing for the entire world to be a screen [28, 33]. Modern works of science fiction (e.g., Minority Report, Ghost in the Shell, and Blade Runner) have explored artistically the manner in which AR could impact society as part of media architecture. However, the challenge of whether AR media architecture is feasible beyond science fiction remains to be addressed.

Despite the availability of AR since the early 2010s [2], it has not yet been established in the field of media architecture. Whereas small scale AR experiences have been developed, they are not yet broadly implemented at the architectural scale. Most early AR focused on viewing 3D content without a persistent spatial or temporal reference to the real world [35]. For this technology to become comparable to classical media architecture [18], it is necessary to anchor AR persistently in the physical environment to support a fully immersive and shareable experience. Here, advances in edge computing and computer vision have produced persistent traces of users' activity that are anchored in the real world and can be accessed remotely by others [39]. Advances in computer vision of real-time environment scanning have made it possible to interact more accurately with AR objects (e.g., the iPad with LIDAR-sensors, the HoloLens) by keeping track of the entire space with, for example, world-locking [12]. With these technologies in place it becomes possible to systematically explore the ways in which AR could extend the notion of media architecture to an augmented space [28].

Another challenge for implementing AR in media architecture is placing virtual data in the physical space. Here, it is necessary to retrieve only meaningful information from the raw data, which we will achieve using the concept of a Digital Twin from industrial research [19, 38]. Digital Twins represent physical objects, processes, or systems by generating a virtual representation of a physical component to model, simulate, and predict its behavior [25]. This enables users to explore past, present, and future activity by modeling higher order processes [25] including social processes [5]. Because a Digital Twin consists of a physical component, a digital component, and the data exchanged between them [19], it lends itself naturally as the backbone of AR media architecture. 
To understand the relation between AR media architecture and classical media architecture, we evaluate screen use along the Reality-Virtuality-Continuum [31] (see Fig. 2). Classical media architecture has remained on the reality end of the continuum, foregoing the benefit of 3D visualizations. Technological limitations such as hardware costs and the ruggedness of devices have limited media architecture to the $2 \mathrm{D}$ world of a screen. Recent work in media architecture has focused on low-cost screens [23] as ubiquitous dashboards to access data [4, 26]. Consequently, there is an increase in the number of screens, which can lead to issues such as light pollution [45]. These issues have led proponents of media architecture to question its purpose beyond art installations and to strive towards reinventing it [15].

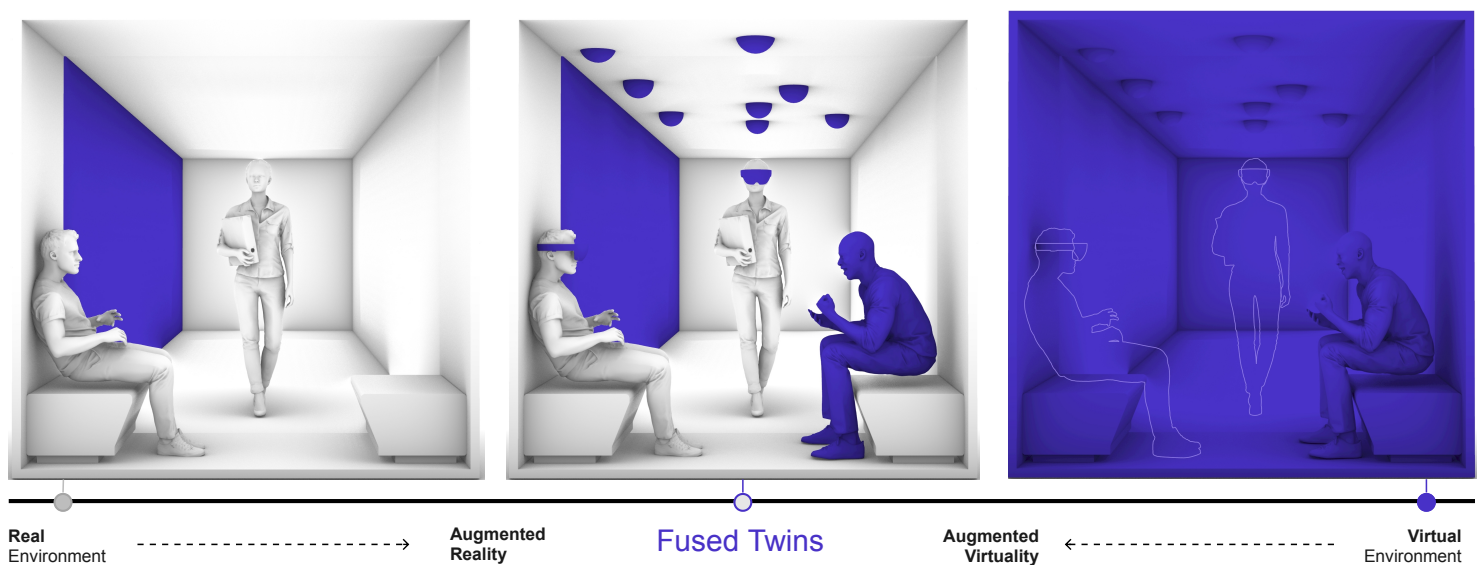

Fig. 2. Media architecture shown across the Reality-Virtuality-Continuum [31]. The media architecture content is displayed in blue and the physical world in white. A progression along the continuum shifts the display in media architecture from external screens to augmentable user screens. The Fused Twins allow an optimal mix of adding virtual content from the Digital Twin and remaining present in the environment.

Offering a novel alternative, AR Digital Twins have been a popular topic since 2018 [7, 10, 24, 27]. Although there are some commonalities with classical media architecture, AR Digital Twins have so far been focused on remote miniaturized viewing of an environment and its processes. This focus of AR Digital Twins differs fundamentally from that of classical media architecture because, with AR, digital information can be embedded in situ in the physical environment. To extend AR Digital Twins to media architecture, it is necessary to fuse the Digital Twin with its Physical Twin. This approach also offers cognitive benefits as it could overcome the limitations of screens to convey spatio-temporal big data. The externalization of cognitive processes into the augmented space allows for the reduction of perceptual and cognitive load when reasoning about data by removing the need for keeping the context in mind [37]. Using AR enables immersive analytics [9], has been shown to reduce task completion time in manufacturing [29, 44], and can help to logically organize the information [32]. Viewed through a Fused Twins, data can be provided in a more natural context, allowing non-experts to engage more easily with the data in an augmented space.

In this late-breaking paper, we describe our first prototype of an AR media architecture that fuses the Digital Twin of a building with its Physical Twin. Beyond the technical proof-of-concept of Fused Twins, we make the data from IoT sensors and occupancy simulations visible for the public promoting the engagement of building occupants and participatory design. Our work demonstrates the potential of AR for media architecture, marking an important step towards fulfilling a societal role beyond the imaginations of science fiction. 


\section{SYSTEM DESIGN \& PROTOTYPE}

We present a first version of the Fused Twins platform that is used as a backbone for AR media architecture (see Fig. 3a). We fuse the Physical Twin in the real world and the Digital Twin in the virtual world using a wide stack of technologies. In the digital realm, we combine a Building Information Model (BIM) [3, 11], virtual environment management [20, 21], and simulations software [17]. In the physical realm, we use computer vision [12, 39], a real building, and 390 IoT sensors [20]. The divide between the physical and the digital is bridged by augmentation through a head-mounted see-through display. Specifically, we employ Microsoft HoloLens 2 (See-through holographic lenses $/ 52^{\circ} \mathrm{FOV}, 8$ cameras, 6DOF tracking, Qualcomm Snapdragon 850/8 cores/2960MHz, 4GB RAM) [30].

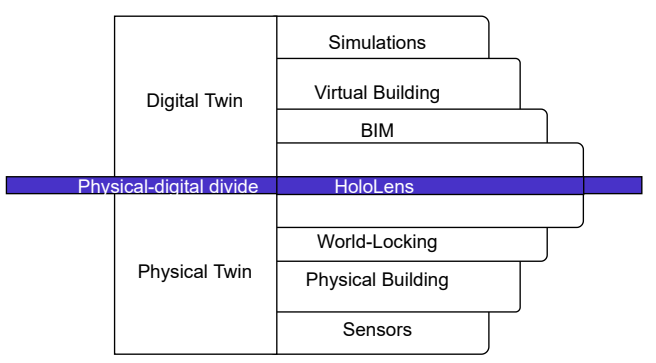

(a) The Fused Twins technology stack.

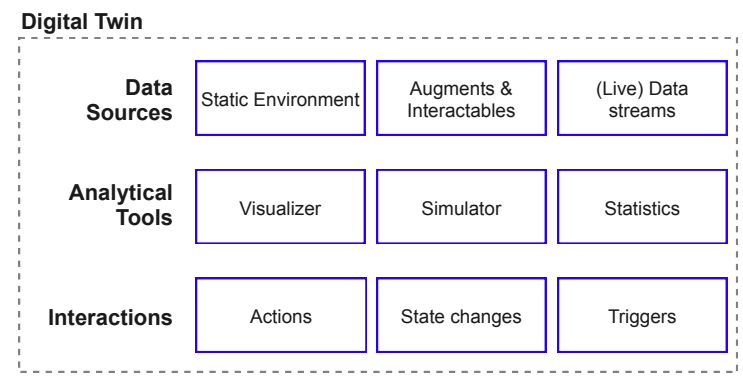

(b) An overview of the features of the Digital Twin.

Fig. 3. (a) The bridge between the digital realm and the physical realm is fused by combining world-locking with a BIM to co-locate the virtual and physical space in a holographic device. (b) The components of the Digital Twin. The data sources provide the information, the analytical tools process the information, and the actions enable users to interact with the data.

The prototype of the Digital Twin is based on Unity3D, extending the Experiments in Virtual Environments (EVE) platform [20,21]. The twin is organized into three types of components: data sources, analytical tools, and interactions (See Fig. 3b). The data sources provide all the information such as the static environment based on a BIM and augments interactables for users (e.g., representations of sensors and agents). The static representation is further expanded with live data streams (e.g., IoT sensor data). The analytical tools provide users with information processing capabilities to visualize the data streams, run simulations, and apply statistics to engage with the data. Finally, the interactions define how users can dynamically communicate with the Fused Twins. Actions allow users to directly manipulate the state of the Fused Twins (e.g., starting a simulation, enabling a visualization). State changes and triggers are similar in that they automatically provide new augmented content. State changes rely on the internal state of the Fused Twins (e.g., the end of a simulation, the display of statistics) whereas triggers are caused by users (e.g., users enter a room and a display is opened). This prototype is limited to demonstrating basic visualizations of sensors and agents.

Integration of Dense Indoor Sensor Networks. Previous research in the building deployed a sensor array of 390 sensors to test a dense indoor sensor network (DISN) [20] with the goal of passively sensing human activity. We reuse this infrastructure to create a live data stream of sensor data for the Digital Twin. The sensor sends the data via LoRaWAN to the EVEREST data server [20], and the physical locations and raw sensor data are streamed from the EVEREST data server via its Representational State Transfer Hypertext Application Language (REST-HAL) interface [34]. The resulting visualization in the Fused Twins (see Fig. 4) enables users to perceive the sensors and their data in the environment. Whereas this initial integration offers limited interaction, it forms the basis for greater participatory opportunities, making the data collection and data itself visible and accessible in a natural way. 


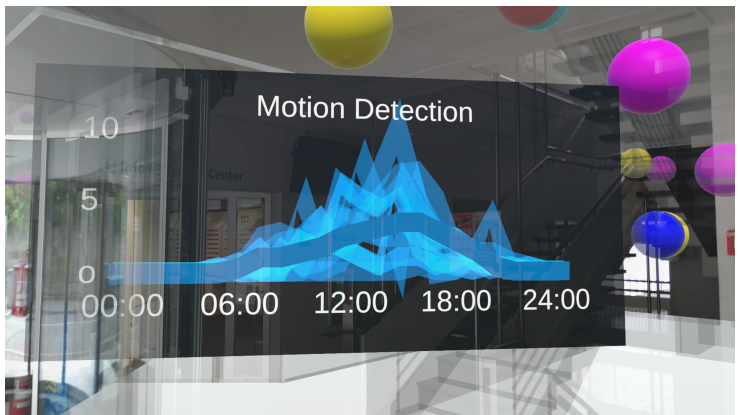

(a) Daily data from a motion sensor at the entrance.

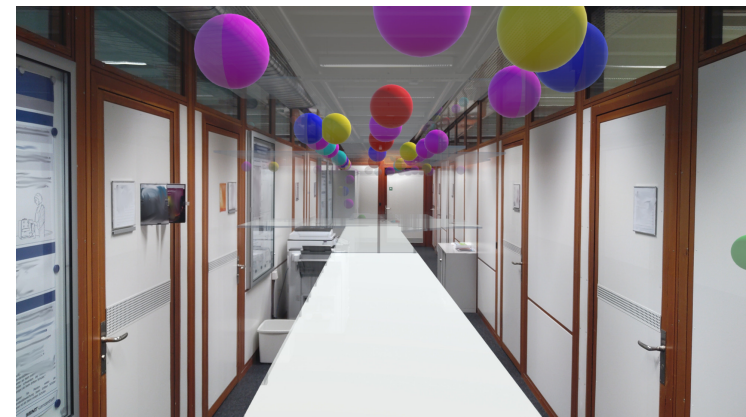

(b) Increased visibility of the many sensors through AR.

Fig. 4. Two snapshots taken live from the HoloLens 2. The loT sensors are installed in the ceiling and out of sight for the users. The colored spheres reveal the locations of sensors in the building (noise: blue; $\mathrm{CO}_{2}$ : red; VOC: cyan; PIR: yellow and magenta; gateway: green). (a) A motion sensor is gaze-activated to display a summary of the collected data.

Integration of Simulated Occupancy Analysis. $\mathrm{Cog} \mathrm{ARCH}$ is an agent-based simulation framework to simulate occupants' behavior in buildings [17] (see Fig. 5a). The spatial input to perform the simulations is the same BIM that underpins the Digital Twin. By integrating $\operatorname{cog} A R C H$ into the Digital Twin, it is possible to provide occupancy analytics based on real-world data (e.g., from sensors) or to predict human behavior based on computational models. The fusion of occupancy analytics into Digital Twins and their perception through AR provides a new form of public engagement that could support a range of applications from wayfinding to emergency evacuation [1,22, 43]. With this approach, occupancy-related (e.g., traces and activities) information may be made available to lay users, enabling participation and informing decision making (see Fig. 5b).

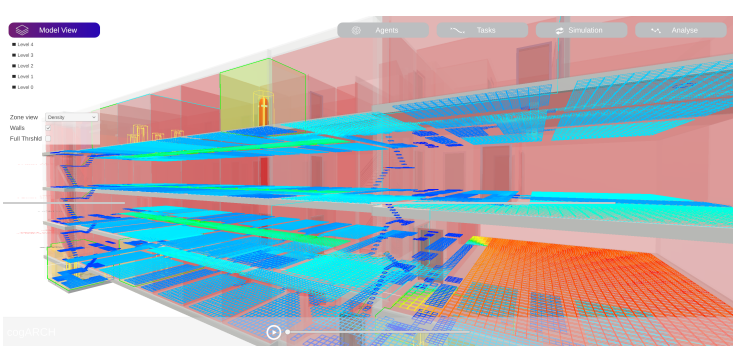

(a) The cogArch framework integration in the Digital Twin.

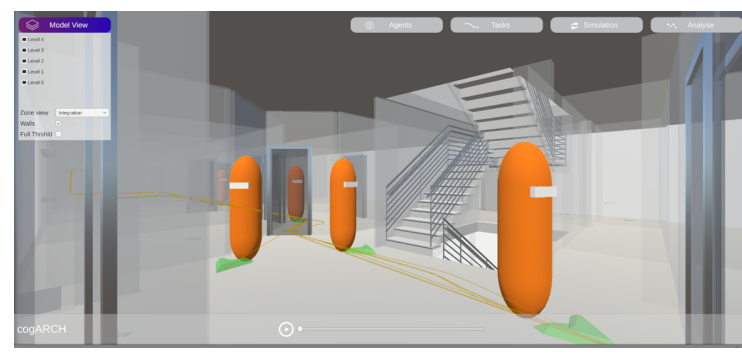

(b) Agents and their traces in the Digital Twin.

Fig. 5. Screenshot of the Digital Twin implementation [17] fused with an agent-based simulation of occupants' movements in the building. For the Fused Twins, refer to Figure 1.

\section{DISCUSSION}

Introducing AR as the medium to media architecture extends three recent exchanges: the environmental cost of media architecture, the goals of media architecture beyond aesthetics, and the participation in creation and consumption of media architecture. First, media architecture can have a strong negative impact on the environment through light and noise pollution $[15,45,46]$. The focus of media architecture has thus become the responsibility to design "more than human" media architecture [15] and address the consequences of designing temporary and environmental costly 
installations. AR media architecture can facilitate these developments because the direct light and noise pollution is limited to the user device. However, the costs of running and maintaining user devices must still be addressed.

Second, media architecture has changed its outlook from aesthetically pleasing art installations to societal issues. As more data is generated, equitable access to the information becomes more challenging. Usually, people will be oblivious the data generation processes [36] around them based on IoT, networks, and building automation. Recent work has therefore focused on regaining accessibility through making the data visible on low-cost screens [23]. We offer another approach through AR that is visually richer and allows people to understand, interact with, and use data in its natural context based on findings in cognitive science. Despite the currently inconclusive evidence on the actual impact of using augmented reality on cognitive load [6, 29, 44], the proposed approach postulates that interactions with the Fused Twins may lower cognitive load by externalizing cognitive processes [37], logically organize the information [32], and enable more participation by a broad range of users (not only experts).

Third, classical media architecture is characterized by its democratic access without a technological barrier from the side of the user [16] but possibly ignores the costs from the side of the creator. In contrast, an AR media architecture approach reverses the burden of these costs. This allows anyone to create augmented content for others to discover but requires physical hardware to access the content. For AR to work, the users have to carry the screens themselves and use them as windows into a virtual world invisible to the naked eye. In this context, AR media design has the potential to inspire more experiences of the data sublime [14]. The latter refers to human awe at the richness of data that can be made accessible through visualizations uncovering the information within the data. As users produce and share their own augmented media architectures, they can strengthen place-making via a pluralistic discourse [14].

The cognitive approach to AR Media Architecture can enable innovative co-creating and co-participation in design processes beyond media architecture. It has been shown that a shared context such a twitter has spawned a thriving ecosystem of co-design tools overcoming the limitations of current software and has enabled innovative applications [40]. Similarly, the Fused Twin could provide a shared spatial context that creates new insights, application, and eventually participation in the use and understanding of the space with regard to environmental and societal questions.

\section{CONCLUSION}

In this paper, we demonstrate a prototype of a Fused Twins as a first step towards AR media architecture. To our knowledge, we are among the first to effectively lay the foundation for how AR media architecture can work. Our approach goes beyond mirroring the physical in the digital by collapsing the Reality-Virtuality-Continuum [31] and fusing the physical and digital representations in situ. The combination of the physical and digital representations allows for a reduction in the cognitive load [37] by providing a natural context for spatio-temporal information. The durable, interactive, and localizable augmentations allow user participation in both the creation and use of AR media architecture. At the same time, we enable engagement with previously invisible data [36] from sources such as DISNs and occupancy simulations. This approach has the potential to increase democratic participation by giving users a better understanding of their surroundings and more equitable access to information. In our future work, we will expand the available interactions for users to explore and arrange the data in its natural context while also enabling the sharing of results with a broader audience. Additionally, we will evaluate the effect of the proposed cognitive approach to AR Media Architecture on the the user's cognitive load by systematically testing user experience.

\section{ACKNOWLEDGMENTS}

This research is funded by ETH Zürich grant ETH-15 16-2. 


\section{REFERENCES}

[1] Leonel Aguilar, Maddegedara Lalith, Muneo Hori, Tsuyoshi Ichimura, and Seizo Tanaka. 2014. A scalable workbench for large urban area simulations, comprised of resources for behavioural models, interactions and dynamic environments. In International Conference on Principles and Practice of Multi-Agent Systems. Springer, Heidelberg, Germany, 166-181.

[2] Dhiraj Amin and Sharvari Govilkar. 2015. Comparative study of augmented reality SDKs. International fournal on Computational Science \& Applications 5, 1 (2015), 11-26.

[3] Salman Azhar. 2011. Building information modeling (BIM): Trends, benefits, risks, and challenges for the AEC industry. Leadership and management in engineering 11, 3 (2011), 241-252.

[4] Michael Batty. 2015. A perspective on city dashboards. Regional Studies, Regional Science 2, 1 (2015), 29-32.

[5] Michael Batty. 2018. Digital twins. Environment and Planning B: Urban Analytics and City Science 45, 5 (2018), 817-820. https://doi.org/10.1177/ 2399808318796416 arXiv:https://doi.org/10.1177/2399808318796416

[6] James Baumeister, Seung Youb Ssin, Neven AM ElSayed, Jillian Dorrian, David P Webb, James A Walsh, Timothy M Simon, Andrew Irlitti, Ross T Smith, Mark Kohler, et al. 2017. Cognitive cost of using augmented reality displays. IEEE transactions on visualization and computer graphics 23 , 11 (2017), 2378-2388.

[7] Tomasz Bednarz, Dominic Branchaud, Florence Wang, Justin Baker, and Malte Marquarding. 2020. Digital Twin of the Australian Square Kilometre Array (ASKAP). In SIGGRAPH Asia 2020 Posters (Virtual Event, Republic of Korea) (SA '20). Association for Computing Machinery, New York, NY, USA, Article 15, 2 pages. https://doi.org/10.1145/3415264.3425462

[8] Moritz Behrens, Nina Valkanova, Ava Fatah gen. Schieck, and Duncan P Brumby. 2014. Smart citizen sentiment dashboard: A case study into media architectural interfaces. In Proceedings of the international symposium on pervasive displays. Association for Computing Machinery, New York, NY, USA, 19-24.

[9] Tom Chandler, Maxime Cordeil, Tobias Czauderna, Tim Dwyer, Jaroslaw Glowacki, Cagatay Goncu, Matthias Klapperstueck, Karsten Klein, Kim Marriott, Falk Schreiber, et al. 2015. Immersive analytics. In 2015 Big Data Visual Analytics (BDVA). IEEE, Hobart, Australia, 1-8.

[10] Oliver Dawkins, Adam Dennett, and Andrew Hudson-Smith. 2018. Living with a Digital Twin: Operational management and engagement using IoT and Mixed Realities at UCL's Here East Campus on the Queen Elizabeth Olympic Park. In 26th GIScience Research UK Conference. GISRUK, Leicester, UK, 6 pages. http://leicester.gisruk.org/programme/

[11] Charles M Eastman, Chuck Eastman, Paul Teicholz, Rafael Sacks, and Kathleen Liston. 2011. BIM handbook: A guide to building information modeling for owners, managers, designers, engineers and contractors. John Wiley \& Sons, Hoboken, NJ, USA.

[12] Mark Finch, Niall Milsom, and Daniel Nagy. 2020. World Locking Tools for Unity. https://github.com/microsoft/MixedReality-WorldLockingToolsUnity.

[13] Patrick Tobias Fischer, Anke Von Der Heide, Eva Hornecker, Sabine Zierold, Andreas Kästner, Felix Dondera, Matti Wiegmann, Fernando Millán, Jonas Lideikis, Aidas Čergelis, et al. 2015. Castle-sized interfaces: an interactive façade mapping. In Proceedings of the 4th International Symposium on Pervasive Displays. Association for Computing Machinery, New York, NY, USA, 91-97.

[14] Claude Fortin. 2016. Recasting the data sublime in media architecture. In Proceedings of the 3rd Conference on Media Architecture Biennale. Association for Computing Machinery, New York, NY, USA, 1-10.

[15] Marcus Foth and Glenda Amayo Caldwell. 2018. More-than-human media architecture. In Proceedings of the 4th Media Architecture Biennale Conference. Association for Computing Machinery, New York, NY, USA, 66-75.

[16] Joel Fredericks, Luke Hespanhol, and Martin Tomitsch. 2016. Not just pretty lights: using digital technologies to inform city making. In Proceedings of the 3rd conference on media architecture biennale. Association for Computing Machinery, New York, NY, USA, 1-9.

[17] Michal Gath-Morad, Leonel Aguilar, Ruth Conroy Dalton, and Christoph Hölscher. 2020. cogARCH: Simulating Wayfinding by Architecture in Multilevel Buildings. In SimAUD 2020/ The 11th annual Symposium on Simulation for Architecture and Urban Design. Society for Modeling \& Simulation International (SCS), Association for Computing Machinery, New York, NY, USA, 20 pages.

[18] Sven Gehring and Alexander Wiethoff. 2014. Interaction with media façades. Informatik-Spektrum 37, 5 (2014), $474-482$.

[19] Michael Grieves and John Vickers. 2017. Digital twin: Mitigating unpredictable, undesirable emergent behavior in complex systems. In Transdisciplinary Perspectives on Complex Systems. Springer, Zürich, Switzerland, 85-113.

[20] Jascha Grübel, Tyler Thrash, Didier Hélal, Robert W. Sumner, Christoph Hölscher, and Victor R. Schinazi. 2021. The Feasibility of Dense Indoor LoRaWAN Towards Passively Sensing Human Presence. In 2021 IEEE International Conference on Pervasive Computing and Communications (PerCom). IEEE, New York, NY, USA, 1-11.

[21] Jascha Grübel, Raphael Weibel, Mike Hao Jiang, Christoph Hölscher, Daniel A Hackman, and Victor R Schinazi. 2016. EVE: A Framework for Experiments in Virtual Environments. In Spatial Cogn. X. Springer, Heidelberg, Germany, 159-176.

[22] Jascha Grübel, Sarah Wise, Tyler Thrash, and Christoph Hölscher. 2019. A cognitive model for routing in agent-based modelling. In AIP Conference Proceedings, Vol. 2116. AIP Publishing LLC, Melville, NY, USA, 4 pages.

[23] Marius Hoggenmueller, Alexander Wiethoff, Andrew Vande Moere, and Martin Tomitsch. 2018. A media architecture approach to designing shared displays for residential internet-of-things devices. In Proceedings of the 4th Media Architecture Biennale Conference. Association for Computing Machinery, New York, NY, USA, 106-117. 
[24] Jade Jiang, Michael Tobia, Robert Lawther, Dominic Branchaud, and Tomasz Bednarz. 2020. Double Vision: Digital Twin Applications within Extended Reality. In ACM SIGGRAPH 2020 Appy Hour (Virtual Event, USA) (SIGGRAPH '20). Association for Computing Machinery, New York, NY, USA, Article 1, 2 pages. https://doi.org/10.1145/3388529.3407313

[25] Maninder Jeet Kaur, Ved P. Mishra, and Piyush Maheshwari. 2020. The Convergence of Digital Twin, IoT, and Machine Learning: Transforming Data into Action. Springer International Publishing, Cham, 3-17. https://doi.org/10.1007/978-3-030-18732-3_1

[26] Rob Kitchin, Tracey P Lauriault, and Gavin McArdle. 2015. Knowing and governing cities through urban indicators, city benchmarking and real-time dashboards. Regional Studies, Regional Science 2, 1 (2015), 6-28.

[27] Oliver Lock, Tomasz Bednarz, and Christopher Pettit. 2019. HoloCity - Exploring the Use of Augmented Reality Cityscapes for Collaborative Understanding of High-Volume Urban Sensor Data. In The 17th International Conference on Virtual-Reality Continuum and Its Applications in Industry (Brisbane, QLD, Australia) (VRCAI '19). Association for Computing Machinery, New York, NY, USA, Article 45, 2 pages. https://doi.org/10.1145 3359997.3365734

[28] Lev Manovich. 2006. The poetics of augmented space. Visual communication 5, 2 (2006), 219-240.

[29] Michael R Marner, Andrew Irlitti, and Bruce H Thomas. 2013. Improving procedural task performance with augmented reality annotations. In 2013 IEEE International Symposium on Mixed and Augmented Reality (ISMAR). IEEE, New York, NY, USA, 39-48.

[30] Microsoft. 2019. Microsoft HoloLens 2: Overview, Features, and Specs. https://www.microsoft.com/en-us/hololens/hardware

[31] Paul Milgram and Fumio Kishino. 1994. A taxonomy of mixed reality visual displays. IEICE TRANSACTIONS on Information and Systems 77, 12 (1994), 1321-1329.

[32] Svetlana Ognjanovic. 2018. Impact of Display Clutter on User Experience. In Design, User Experience, and Usability: Theory and Practice, Aaron Marcus and Wentao Wang (Eds.). Springer International Publishing, Cham, 125-140.

[33] Callum Parker, Waldemar Jenek, Soojeong Yoo, and Youngho Lee. 2018. Augmenting Cities and Architecture with Immersive Technologies. In Proceedings of the 4th Media Architecture Biennale Conference. Association for Computing Machinery, New York, NY, USA, 174-177.

[34] Leonard Richardson, Mike Amundsen, Michael Amundsen, and Sam Ruby. 2013. RESTful Web APIs: Services for a Changing World. O'Reilly Media, Sebastopol, CA, USA.

[35] Kong Ruan and Hong Jeong. 2012. An augmented reality system using Qr code as marker in android smartphone. In 2012 Spring Congress on Engineering and Technology. IEEE, New York, NY, USA, 1-3.

[36] Selena Savic and Teresa Heitor. 2014. Probing the network: architecturality of wireless infrastructure. In Proceedings of the 2Nd Media Architecture Biennale Conference: World Cities. Association for Computing Machinery, New York, NY, USA, 69-78.

[37] Mike Scaife and Yvonne Rogers. 1996. External cognition: how do graphical representations work? International journal of human-computer studies 45, 2 (1996), 185-213.

[38] Fei Tao, Meng Zhang, and A.Y.C. Nee. 2019. Chapter 2 - Applications of Digital Twin. In Digital Twin Driven Smart Manufacturing, Fei Tao, Meng Zhang, and A.Y.C. Nee (Eds.). Academic Press, Cambridge, MA, USA, 29-62. https://doi.org/10.1016/B978-0-12-817630-6.00002-3

[39] Craig Treasure, Mehran Azimi, Mark Schofield, Ali Emami, Paris Morgan, Rene Schulte, Patrick Cook, and Radford Parker. 2019. Azure Spatial Anchors Samples. https://github.com/Azure/azure-spatial-anchors-samples.

[40] Hannah Twigg-Smith, Jasper Tran O’Leary, and Nadya Peek. 2021. Tools, Tricks, and Hacks: Exploring Novel Digital Fabrication Workflows on \#PlotterTwitter. In Proceedings of the 2021 CHI Conference on Human Factors in Computing Systems (Yokohama, Japan) (CHI '21). Association for Computing Machinery, New York, NY, USA, Article 594, 15 pages. https://doi.org/10.1145/3411764.3445653

[41] Ben van Berkel, Filippo Lodi, and Wael Sami Batal. 2018. Responsive Technologies of Social Health. In Proceedings of the 4th Media Architecture Biennale Conference. Association for Computing Machinery, New York, NY, USA, 45-54.

[42] Jos P Van Leeuwen, Klaske Hermans, Antti Jylhä, Arnold Jan Quanjer, and Hanke Nijman. 2018. Effectiveness of virtual reality in participatory urban planning: A case study. In Proceedings of the 4th Media Architecture Biennale Conference. Association for Computing Machinery, New York, NY, USA, 128-136.

[43] MLL Wijerathne, Leonel Aguilar, Muneo Hori, Tsuyoshi Ichimura, and Seizo Tanaka. 2013. HPC enhanced large urban area evacuation simulations with vision based autonomously navigating multi agents. Procedia Computer Science 18 (2013), 1515-1524.

[44] Zhen Yang, Jinlei Shi, Wenjun Jiang, Yuexin Sui, Yimin Wu, Shu Ma, Chunyan Kang, and Hongting Li. 2019. Influences of augmented reality assistance on performance and cognitive loads in different stages of assembly task. Frontiers in psychology 10 (2019), 1703.

[45] Karolina M Zielinska-Dabkowska. 2014. Critical perspectives on media architecture: is it still possible to design projects without negatively affecting urban nighttime environments and will the future remain dynamic, bright and multi-colored?. In Proceedings of the 2nd Media Architecture Biennale Conference: World Cities. Association for Computing Machinery, New York, NY, USA, 101-108.

[46] Karolina M Zielinska-Dabkowska and Kyra Xavia. 2019. Global Approaches to Reduce Light Pollution from Media Architecture and Non-Static, Self-Luminous LED Displays for Mixed-Use Urban Developments. Sustainability 11, 12 (2019), 3446. 